\title{
Oxidative Addition of Aryl Halides to a Ni(I)-Bipyridine Complex
}

\author{
Stephen I. Ting, Wendy L. Williams, Abigail G. Doyle* \\ Department of Chemistry, Princeton University, Princeton, New Jersey 08544, United States \\ Department of Chemistry and Biochemistry, University of California, Los Angeles, California 90095, United States
}

\begin{abstract}
The oxidative addition of aryl halides to bipyridine- or phenanthroline-ligated nickel(I) is a commonly proposed step in nickel catalysis. However, there is a scarcity of complexes of this type that both are well-defined and undergo oxidative addition with aryl halides, hampering organometallic studies of this process. We report the synthesis of a well-defined $\mathrm{Ni}(\mathrm{I}) \mathrm{complex}$, $\left[\left({ }^{\mathrm{CO}_{2} \mathrm{E}}\right.\right.$ bpy $) \mathrm{NiCl}_{4}(\mathbf{1})$. Its solution-phase speciation is characterized by a significant population of monomer and a redox equilibrium that can be perturbed by $\pi$-acceptors and $\sigma$-donors. 1 reacts readily with aryl bromides, and mechanistic studies are consistent with a mechanism proceeding through an initial $\mathrm{Ni}(\mathrm{I}) \rightarrow \mathrm{Ni}(\mathrm{III})$ oxidative addition. Such a process was demonstrated stoichiometrically for the first time, affording a structurally characterized Ni(III) aryl complex.
\end{abstract}

\section{INTRODUCTION}

Nickel catalysis has seen tremendous advances in recent years, resulting in the development of diverse methodologies for the formation of $\mathrm{C}-\mathrm{C}$ and $\mathrm{C}$-heteroatom bonds (Figure 1A). ${ }^{1-7}$ These catalytic reactions span fields such as $\mathrm{Ni} /$ photoredox, $\mathrm{Ni} /$ electrocatalysis and cross-electrophile coupling, and are enabled by the facile accessibility of numerous Ni oxidation states. ${ }^{8}$ Crucially, this includes not only the common $\mathrm{Ni}(0)$ and $\mathrm{Ni}(\mathrm{II})$ oxidation states, but also the odd-electron $\mathrm{Ni}(\mathrm{I})$ and $\mathrm{Ni}(\mathrm{III})$ oxidation states. Consequently, 1- and 2-electron processes can be combined in many ways to execute distinct transformations. ${ }^{8,9}$

An important and widely proposed mechanistic event is the oxidative addition of aryl halides to $\mathrm{Ni}(\mathrm{I})$, generating a $\mathrm{Ni}(\mathrm{III})$ aryl complex (Figure 1A). The importance of this process is twofold: first, oxidative addition to $\mathrm{Ni}(\mathrm{I})$ activates an aryl halide substrate for cross-coupling; second, it provides access to the $\mathrm{Ni}(\mathrm{III})$ oxidation state, which is more electrophilic than $\mathrm{Ni}(\mathrm{II})$ and more readily undergoes challenging reductive eliminations. The significance of oxidative addition to $\mathrm{Ni}(\mathrm{I})$ is perhaps best illustrated by studies demonstrating that $\mathrm{C}$-heteroatom crosscouplings may proceed through a self-sustaining $\mathrm{Ni}(\mathrm{I}) / \mathrm{Ni}(\mathrm{III})$ catalytic cycle. ${ }^{10-13}$

Unfortunately, the sparsity of well-defined $\mathrm{Ni}(\mathrm{I})$ complexes has hampered the use of classical organometallic tools for studying this oxidative addition process and its underlying mechanism. This holds true for systems bearing ligands from the bipyridine (bpy) or phenanthroline (phen) classes, which are often utilized in synthetic

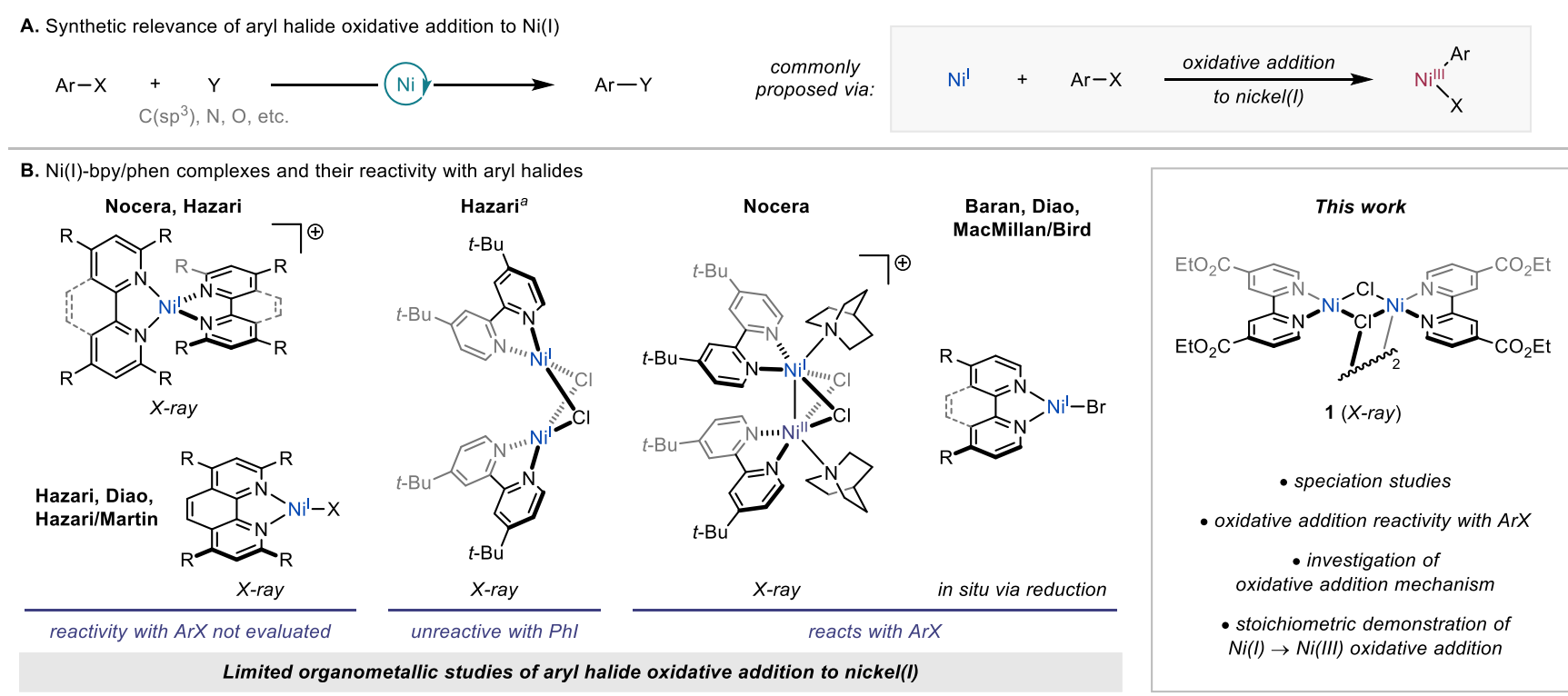

Figure 1. Oxidative addition of aryl halides to $\mathrm{Ni}(\mathrm{I}) \cdot{ }^{a}$ This formal $\mathrm{Ni}(\mathrm{I})$ complex is best described as $\left[\left(\mathrm{dtbbpy}^{\circ}\right) \mathrm{Ni}^{\mathrm{II}} \mathrm{Cl}\right]_{2}$. 
methodologies. ${ }^{14-17}$ In fact, of the few Ni(I)-bpy/phen complexes that have been prepared and structurally characterized, ${ }^{18-}$ ${ }^{22}$ only one (a $\mathrm{Ni}_{2}(\mathrm{I}, \mathrm{II})$ dimer from the Nocera group) has been demonstrated to react with aryl bromides (Figure 1B). ${ }^{10}$ Studies by Baran, Diao, and MacMillan/Bird have taken additional key steps towards studying $\mathrm{Ni}(\mathrm{I})$-bpy/phen species generated in situ through reduction (chemically, ${ }^{20}$ electrochemically, ${ }^{23}$ or radiolytically ${ }^{24}$, respectively). These studies have together demonstrated that monomeric $\mathrm{Ni}(\mathrm{I})$-bpy/phen species can react with aryl halides. However, the precise mechanism of oxidative addition is not yet well understood, and no direct experimental evidence has been provided for the formation of $\mathrm{Ni}$ (III) upon oxidative addition to a Ni(I)-bpy/phen complex. Notably, spectroscopic evidence for a $\mathrm{Ni}(\mathrm{I}) \rightarrow \mathrm{Ni}$ (III) oxidative addition has been obtained with other ligand scaffolds, but remains rare. ${ }^{25,26}$

Access to a well-defined $\mathrm{Ni}(\mathrm{I})$ complex that reacts with aryl halides would enable thorough experimental mechanistic studies of the oxidative addition process. This would be particularly valuable as routine density functional theory calculations fail to accurately compute electronic structures and energies of Ni-bipyridine systems. ${ }^{27,28}$ To this end, we report the synthesis of the well-defined complex $\left[\left(\mathrm{CO}_{2} \mathrm{Et} b p y\right) \mathrm{NiCl}_{4}\right.$ (1) and present our findings regarding its speciation and oxidative addition with aryl halides $\left({ }^{\mathrm{CO}_{2} \mathrm{Et}} \mathrm{bpy}=\right.$ diethyl $2,2^{\prime}$-bipyridine-4,4'-dicarboxylate).

\section{RESULTS AND DISCUSSION}

Synthesis and characterization of $\left[\left(\mathrm{CO}_{2} \mathrm{Et} b p y\right) \mathrm{NiCl}_{4}(1)\right.$. In a prior project aimed at studying the photophysics and photochemistry of Ni complexes, we prepared a series of complexes including $\left({ }^{\mathrm{CO}_{2} \mathrm{Et}} \mathrm{bpy}\right) \mathrm{Ni}^{\mathrm{II}}(o-\mathrm{Tol}) \mathrm{Cl}^{29}$ Serendipitously, we found that upon prolonged standing in THF solution, this complex converts to $o, o^{\prime}$-bitoluene and a deep purple crystalline solid (Figure 2A). X-ray crystallography revealed the formation of $\left[\left({ }^{\mathrm{CO}_{2} \mathrm{Et} b p y}\right) \mathrm{NiCl}\right]_{4}(\mathbf{1})$, a tetrameric formal $\mathrm{Ni}(\mathrm{I})$ complex that is stable for at least months under inert atmosphere (Figure 2B). Based on kinetic studies of $\mathrm{Ni}(\mathrm{cod})_{2}$ /bpy-mediated homocoupling and related precedent from the Hazari group, 1 presumably arises from a transmetalation that produces $\left({ }^{\mathrm{CO}_{2}} \mathrm{Et} b p y\right) \mathrm{Ni}^{\mathrm{II}}(O-$ $\mathrm{Tol})_{2}$ and $\left({ }^{\mathrm{CO}_{2} \mathrm{Et}} \mathrm{bpy}\right) \mathrm{Ni}^{\mathrm{II}} \mathrm{Cl}_{2} \cdot{ }^{19,30} \mathbf{1}$ would then result from reductive elimination of biaryl, comproportionation and aggregation.

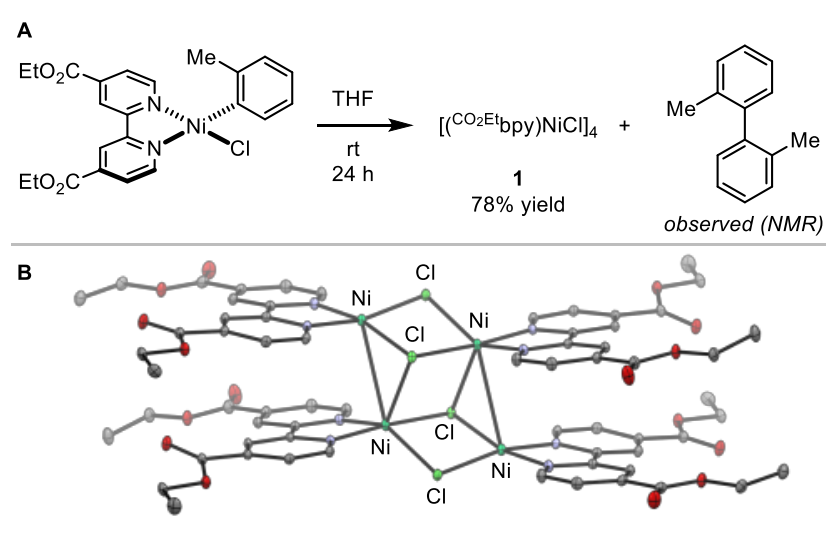

Figure 2. (A) Synthesis of 1. (B) Solid-state molecular structure of $\mathbf{1}$ at $30 \%$ probability ellipsoids. Hydrogen atoms omitted for clarity.
Having synthesized 1, we sought to determine how its speciation differs in the solid vs. solution phases. A solid sample of 1 was measured to have a magnetic moment of $4.5 \mu_{\mathrm{B}}$, consistent with an $S=2$ ground state. On the other hand, a frozen solution of 1 in THF/PhMe (2:1) afforded an EPR spectrum with a signal at $g_{\text {avg }}=2.193$, indicative of an $S=1 / 2$ complex (Figure 3A). The $g$-value is similar to those of well-characterized monomeric (phen) $\mathrm{Ni}^{\mathrm{I}}$ (halide) complexes $\left(g_{\text {avg }}=2.21-\right.$ 2.24), ${ }^{20,21}$ and we therefore assign the EPR signal to monomeric 1. The $g_{\text {avg }}$ value of $\mathbf{1}$ deviates substantially from the free electron value $\left(g_{\mathrm{e}}=2.002\right)$, indicating a radical with substantial metal-centered character.

In solution, the monomeric form of 1 accounts for $30 \%$ of the $\mathrm{Ni}$, as determined by double integration of the EPR signal against a $\mathrm{Cu}$ (II) external standard. Thus, the monomeric form is a significant contributor to the resting state of $\mathbf{1}$ in solution (Figure 3C, top). Notably, this contrasts with the Hazari group's observation that the related dtbbpy complex $\left[(\mathrm{dtbbpy}) \mathrm{Ni}^{\mathrm{I}} \mathrm{Cl}\right]_{2}$ does not exist as a monomer to any measurable extent (dtbbpy $=4,4^{\prime}$-di-tert-butyl-2,2'-bipyridine).${ }^{19}$ For the remaining $70 \%$ of $\mathrm{Ni}$ in 1, we initially assumed that this would comprise EPRsilent dimer and/or tetramer. However, the ${ }^{1} \mathrm{H}$ NMR spectrum of 1 in THF- $d_{8}$ revealed a substantial amount of the Ni(0) complex $\left({ }^{\mathrm{CO}_{2} \mathrm{Et}} \mathrm{bpy}\right)_{2} \mathrm{Ni}^{0}(\mathbf{2})$, which was verified by independent synthesis and accounts for $40 \%$ of the Ni (Figure 3B, see SI). This established the existence of a redox equilibrium between monomeric 1 and the $\mathrm{Ni}(0)$ complex 2 (Figure 3C). Complex 2 presumably forms via a disproportionation that also generates $\mathrm{Ni}^{\mathrm{II}} \mathrm{Cl}_{2}$ to account for the mass and redox balance.
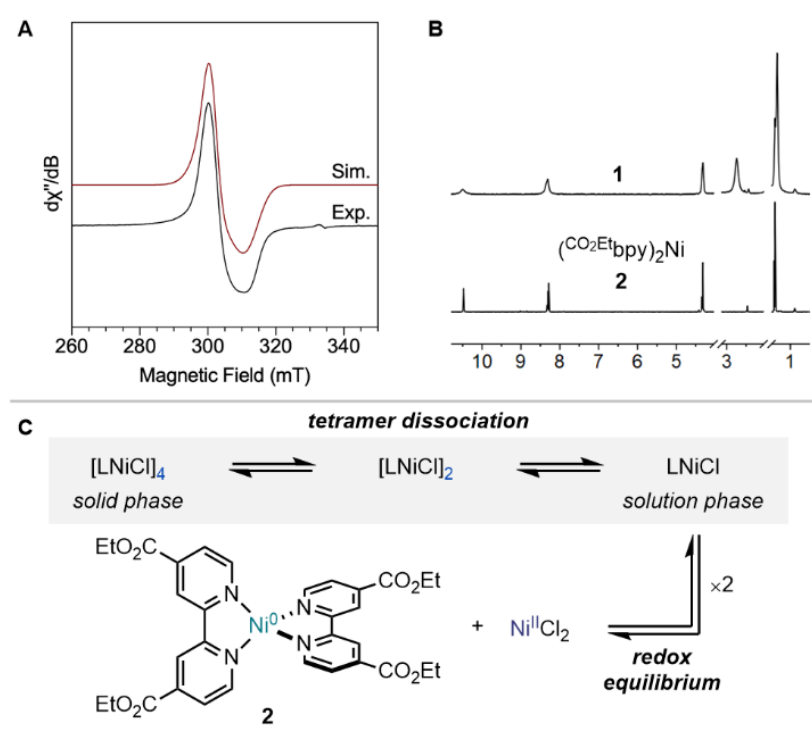

Figure 3. (A) X-band EPR spectrum of 1 (2:1 THF/PhMe, $25 \mathrm{~K})$. Simulation parameters: $g_{1}=2.218, g_{2}=2.215, g_{3}=2.147$. (B) ${ }^{1} \mathrm{H}$ NMR (THF- $d_{8}$ ) of $\mathbf{1}$ and 2. (C) Solution-phase speciation of $\mathbf{1}$. L = $\mathrm{CO}_{2} \mathrm{Et}$ bpy.

To further evaluate this redox equilibrium, we examined the effect of adding $\pi$-accepting and $\sigma$-donating species. These have been demonstrated to cause disproportionation of $\mathrm{Ni}(\mathrm{I}) / \mathrm{N}$-heterocyclic carbene complexes by providing a driving force to form $\mathrm{Ni}(0)$ or $\mathrm{Ni}(\mathrm{II})$ species. ${ }^{31,32}$ Indeed, treating 1 with $\pi$-accepting dimethyl fumarate ( $\mathrm{dmfu}$ ) led to full disproportionation within seconds, forming $\left({ }^{\mathrm{CO}_{2} \mathrm{Et}} \mathrm{bpy}\right) \mathrm{Ni}^{0}(\mathrm{dmfu})$ and 
$\left({ }^{\mathrm{CO}_{2} \mathrm{Et}}\right.$ bpy) $\mathrm{Ni}^{\mathrm{II}} \mathrm{Cl}_{2}$ in a 1:1 ratio (Scheme $\left.1 \mathrm{~A}\right) .{ }^{33}$ The less $\pi$-accepting acetophenone or $(E)-4,4^{\prime}$-di-tert-butylstilbene did not interact with 1 to any observable extent. However, transient $\pi$-complexes with these compounds cannot be ruled out.

Scheme 1. Perturbation of redox equilibrium by (A) $\pi$-acceptors or (B) $\sigma$-donors. $\mathrm{L}={ }^{\mathrm{CO} 2 \mathrm{Et}}$ bpy.
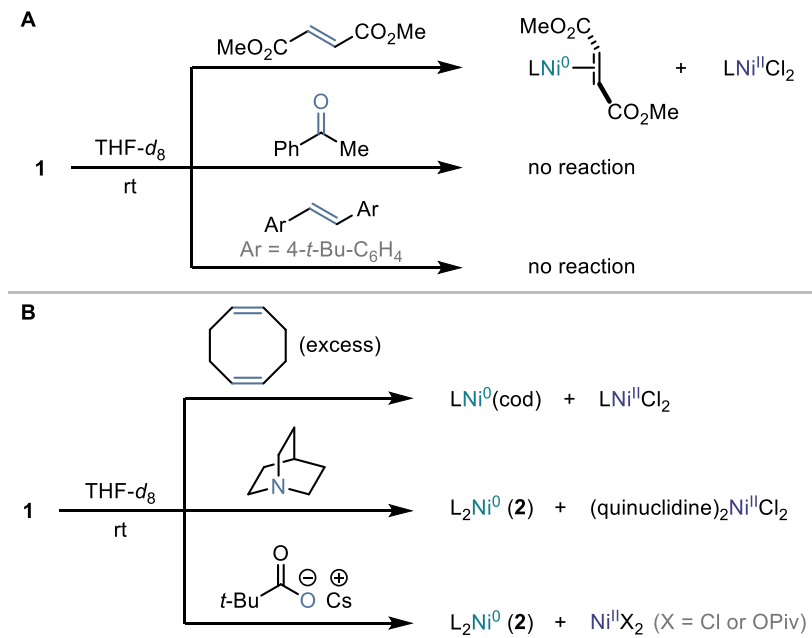

The effect of more strongly $\sigma$-donating species on the redox equilibrium of 1 was also determined (Scheme 1B). Treating 1 with excess 1,5-cyclooctadiene (cod) led to consumption of $\mathbf{1}$, with cod being incorporated in the form of $\left({ }^{\mathrm{CO}_{2} \mathrm{Et}} \mathrm{bpy}\right) \mathrm{Ni}^{0}(\mathrm{cod})$. This may be driven by cod increasing the electron density at $\mathrm{Ni}$, enabling more effective $\pi$-backbonding into the ${ }^{\mathrm{CO}_{2} \mathrm{Et}}$ bpy ligand. Disproportionation can also be favored by donors that instead stabilize the $\mathrm{Ni}$ (II) oxidation state, including quinuclidine and CsOPiv. The latter observation is notable, contrasting with the fact that sterically demanding phen ligands can afford stable $\mathrm{Ni}(\mathrm{I})$ carboxylate complexes. ${ }^{21}$

Taken together, these findings point to a delicate redox balance, where sufficiently strong $\sigma$-donors and $\pi$-acceptors can both favor disproportionation away from the $\mathrm{Ni}(\mathrm{I})$ oxidation state. The position of this redox equilibrium is likely dependent on the ancillary ligand and precise experimental conditions. Nonetheless, it is likely an important consideration for the development of reactions where $\mathrm{Ni}(\mathrm{I})$ intermediates play key roles.

Stoichiometric oxidative addition studies. Our attention shifted to investigating the oxidative addition reactivity of $\mathbf{1}$ with aryl halides. Upon treatment with $\mathrm{PhBr}$ at room temperature in THF- $d_{8}, 1$ was fully consumed within minutes. However, $\mathrm{Ni}(\mathrm{III})$ products were not formed, and ${ }^{1} \mathrm{H}$ NMR instead revealed

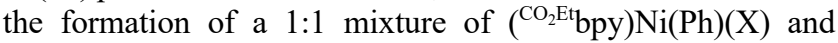
$\left({ }^{\mathrm{CO}_{2} \mathrm{Et}}\right.$ bpy) $\mathrm{NiX}_{2}$ (eq. $1 ; \mathrm{X}=\mathrm{Cl}$ or $\left.\mathrm{Br}\right) .{ }^{33}$ While this may proceed through the intermediacy of $\mathrm{Ni}$ (III) (vide infra), this overall process constitutes a formal bimetallic oxidative addition similar to prior reports. ${ }^{10,20}$ We note that only 0.5 equivalents of $\mathrm{PhBr}$ are consumed per Ni center, even when excess $\mathrm{PhBr}$ is added.

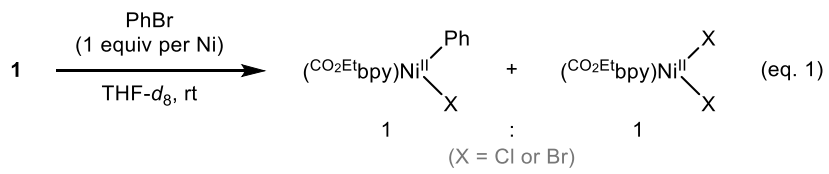

The facile reactivity is noteworthy, as numerous $\mathrm{Ni}(\mathrm{I})$ complexes react only with alkyl and not aryl halides. ${ }^{19,34}$ More striking is the high oxidative addition reactivity of $\mathbf{1}$ compared to the lack of reactivity documented for its dtbbpy counterpart [(dtbbpy) $\left.\mathrm{Ni}^{\mathrm{I}} \mathrm{Cl}\right]_{2}$, despite $\mathbf{1}$ bearing a less electron-donating ligand. ${ }^{19}$ We believe this is because a reactive monomeric form is accessible to $\mathbf{1}$, a notion that is supported through kinetic measurements (vide infra).

Reactivity with other aryl electrophiles was also examined (Scheme 2). 4-Iodotoluene reacted analogously to aryl bromides, rapidly resulting in full conversion to the products of a formal bimetallic oxidative addition. 4-(Trifluoromethyl)phenyl triflate reacted to form biaryl with no observable Ni products. In contrast, the more electron-rich $p$-tolyl triflate was unreactive over $24 \mathrm{~h}$, which was also the case for aryl chlorides. Heating was precluded by decomposition of 1 in THF- $d_{8}$ at 60 ${ }^{\circ} \mathrm{C}$.

Scheme 2. Reactivity with other aryl electrophiles.

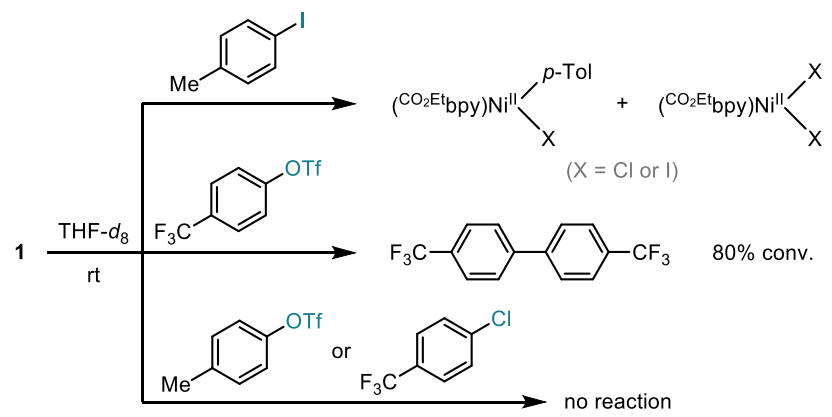

Possible oxidative addition mechanisms. Having established the reactivity of $\mathbf{1}$ towards oxidative addition, we sought to investigate the mechanism of this process, which is defined by multiple characteristics outlined in Figure 4:

(A) The intermediate oxidation states accessed (A1-A4). In one possibility, a Ni(III) intermediate may be accessed by 2 electron oxidative addition to $\mathrm{Ni}(\mathrm{I})$, which is followed by comproportionation with a second equivalent of $\mathrm{Ni}(\mathrm{I}) \cdot{ }^{10,12}$ A second possibility is that a $\mathrm{Ni}(0)$ intermediate may be accessed by disproportionation of $\mathrm{Ni}(\mathrm{I})$, with the generated $\mathrm{Ni}(0)$ being responsible for oxidative addition. A third possibility is a stepwise radical process, where a radical is generated by one $\mathrm{Ni}$ center then captured at another. ${ }^{35}$ Lastly, a concerted dinuclear process is also possible. ${ }^{36,37}$

(B) The nuclearity of the reactive Ni species (B1-B3). Reaction may occur through a monomeric, dimeric, or tetrameric complex.

(C) The mechanism by which the $\mathrm{C}-\mathrm{Br}$ bond undergoes activation (C1-C5). Possibilities include concerted oxidative additions (monometallic ${ }^{38-40}$ or bimetallic ${ }^{36,37}$ ), halogen atom abstraction, ${ }^{34}$ single electron transfer ${ }^{41}$ and nucleophilic aromatic substitution $\left(\mathrm{S}_{\mathrm{N}} \mathrm{Ar}\right){ }^{42}$ Broadly, these describe whether $\mathrm{C}-$ $\mathrm{Br}$ bond activation is a 1- or 2-electron process, and the degree to which it is concerted or stepwise.

With these mechanistic possibilities delineated, we undertook the task of evaluating them experimentally. 


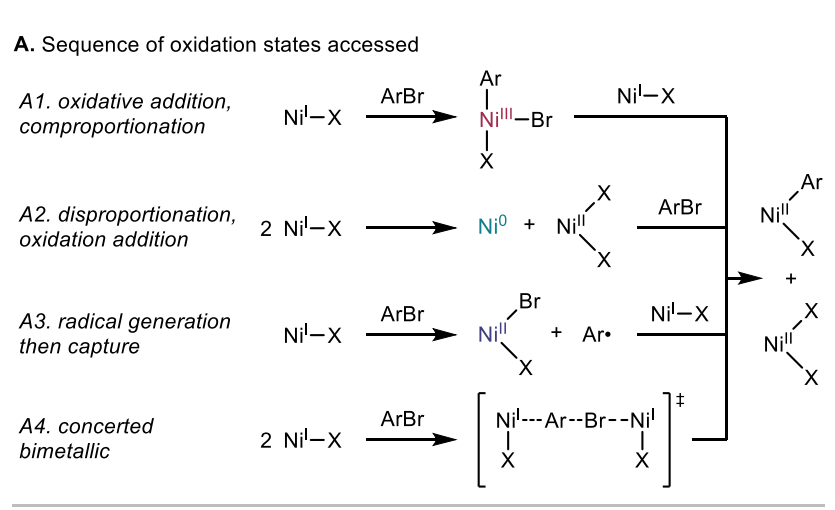

B. Nuclearity of reactive $\mathrm{Ni}$ species

B1. monomer $\rightleftharpoons$ B2. dimer $\rightleftharpoons$ B3. tetramer

C. Mechanism of $\mathrm{C}-\mathrm{Br}$ bond activation

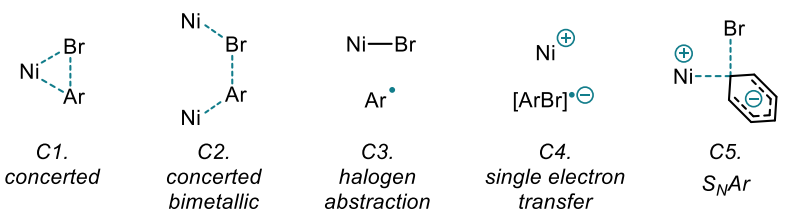

Figure 4. Mechanistic possibilities for oxidative addition.

Mechanistic experiments. Kinetic studies. We began our mechanistic inquiry of the oxidative addition with kinetic studies. The oxidative addition of $\mathrm{PhBr}$ to 1 was conducted under pseudo-first-order conditions (excess $\mathrm{PhBr}$ ), monitoring consumption of 1 by loss of absorbance at $800 \mathrm{~nm}$ (Figure 5A). A plot of $\ln [1] /[1]_{0}$ vs. time was linear through six half-lives, indicating a first-order dependence on 1 (Figure 5B). Varying [PhBr] gave a plot of $k_{\mathrm{obs}} \mathrm{vs.}[\mathrm{PhBr}]$ that was linear, indicating a first-order dependence on $\mathrm{PhBr}$ (Figure 5C). The slope revealed a second-order rate constant of $7.1 \pm 0.3 \mathrm{M}^{-1} \mathrm{~s}^{-1}$. Thus, 1 reacts with $\mathrm{PhBr}$ more rapidly than $\mathrm{Ni}^{0}\left(\mathrm{PEt}_{3}\right)_{4}$ does under the same conditions $\left(2.9 \mathrm{M}^{-1} \mathrm{~s}^{-1}\right)$, despite 1 having a higher formal oxidation state and a less electron-donating ligand. ${ }^{41}$ Both of these rate constants are over $1000 \times$ smaller than that of oxidative addition of $\mathrm{PhI}$ to radiolytically generated (dtbbpy) $\mathrm{Ni}^{\mathrm{I}} \mathrm{Br}$ $\left(2.2 \times 10^{4} \mathrm{M}^{-1} \mathrm{~s}^{-1}\right.$ in DMF $){ }^{24}$
A

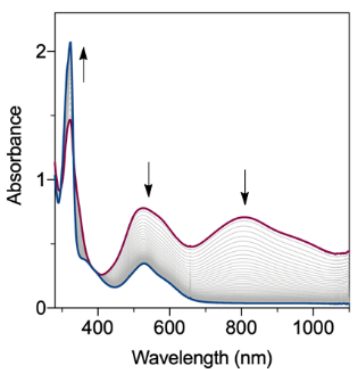

C
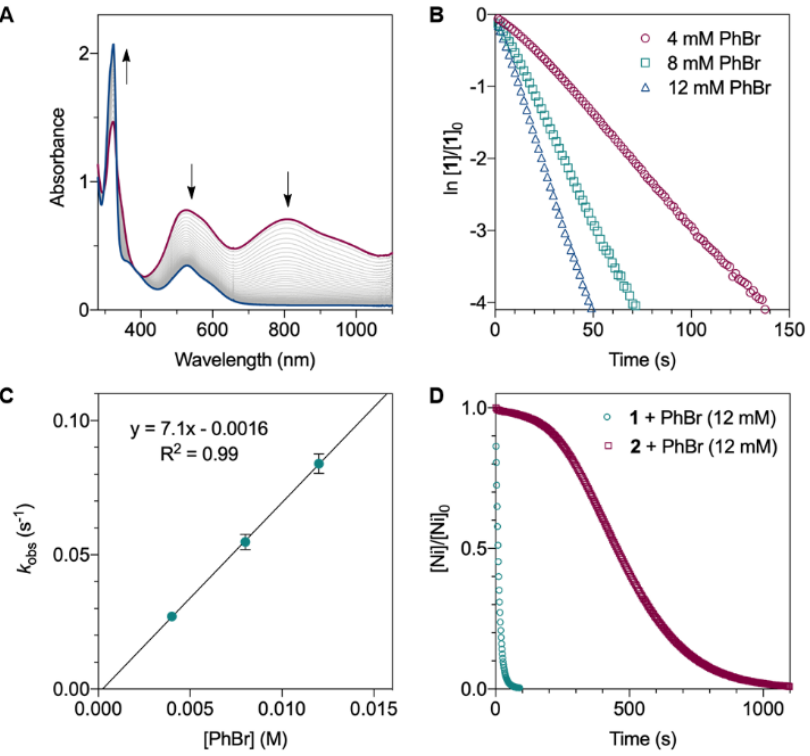

Figure 5. Kinetic studies of oxidative addition of $\mathrm{PhBr}$ to 1 in THF at $26{ }^{\circ} \mathrm{C}$. (A) Representative UV-Vis traces; red = initial; blue = final. Arrows indicate the direction of spectral evolution. (B) Firstorder dependence on 1. (C) First-order dependence on PhBr. (D) Reactivity of 1 vs. 2 with $\mathrm{PhBr}$.

The first-order dependence on $\mathbf{1}$ and $\mathrm{PhBr}$ is most readily interpreted as reflecting a direct reaction between a resting state of 1 with $\mathrm{PhBr}$, with no requirement for (dis)aggregation. The low-valent resting states comprise monomeric species, namely monomeric 1 and $\mathrm{Ni}(0)$ complex 2, (eq. 1). Thus, the first-order dependence excludes reaction through dimers and tetramers (B2 and B3) and through a concerted bimetallic mechanism (A4 and $\mathrm{C} 2$ ). Reactivity of the two resting states was distinguished using independently prepared $\mathbf{2}$. Under identical conditions, 2 reacted more slowly than $\mathbf{1}$ and with an induction period (Figure 5D). This ruled out oxidative addition to 2 , suggesting that the monomeric $\mathrm{Ni}(\mathrm{I})$ species $\left({ }^{\mathrm{CO}_{2} \mathrm{Et}} \mathrm{bpy}\right) \mathrm{NiCl}$ is responsible for oxidative addition. Strictly speaking, though, oxidative addition may occur through alternative $\mathrm{Ni}(0)$ species (e.g., $\left.\mathrm{L}_{1} \mathrm{Ni}^{0}\right)$. Unfortunately, our attempts to interrogate this through additional experimentation were not fruitful (see Figure S21). As a result, we shifted our focus to the mechanism of $\mathrm{C}-\mathrm{Br}$ bond activation (Figure 4C).

Electronic and steric dependence. To probe the mechanism of $\mathrm{C}-\mathrm{Br}$ activation, we evaluated the electronic dependence of the oxidative addition process. A Hammett analysis was conducted using a series of 4-substituted bromobenzenes (Figure 6). All underwent analogous oxidative additions that were first order in both 1 and aryl bromide, and the measured rate constants afforded a linear Hammett plot. These findings indicate that a single mechanism is conserved across aryl bromides. The slope of the Hammett plot is $\rho=+1.1$, which is similar to the $\rho$ value of +1.3 measured for the reaction of radiolytically generated (dtbbpy) $\mathrm{Ni}^{\mathrm{I}} \mathrm{Br}$ with aryl iodides. ${ }^{24,43}$ The modest $\rho$ value is inconsistent with oxidative addition occurring through a single electron transfer $(\mathrm{C} 4, \rho \sim+4)^{41}$ or $\mathrm{S}_{\mathrm{N}}$ Ar-type $(\mathrm{C} 5, \rho \sim+5)^{42}$ process. Instead, it is consistent with either a concerted oxidative addition $(\mathrm{C} 1, \rho \sim+2)^{44,45}$ or a halogen atom abstraction $(\mathrm{C} 3, \rho \sim$ $+1)^{46}$. 


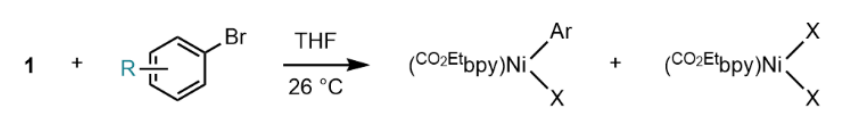

\begin{tabular}{|c|c|c|}
\hline$R$ & $k\left(\mathrm{M}^{-1} \mathrm{~s}^{-1}\right)$ & $k_{\text {rel }}$ \\
\hline 4-COMe & $56 \pm 3$ & 7.9 \\
\hline $4-\mathrm{CF}_{3}$ & $40 \pm 2$ & 5.7 \\
\hline $4-\mathrm{Cl}$ & $16.3 \pm 0.5$ & 2.3 \\
\hline 4-Ph & $13.1 \pm 0.5$ & 1.8 \\
\hline $4-\mathrm{H}$ & $7.1 \pm 0.3$ & 1 \\
\hline 4-Me & $5.0 \pm 0.3$ & 0.70 \\
\hline 4-OMe & $3.4 \pm 0.3$ & 0.48 \\
\hline 2-Me & $1.51 \pm 0.09$ & 0.21 \\
\hline $2,6-\mathrm{Me}_{2}$ & $0.070 \pm 0.007$ & 0.0099 \\
\hline
\end{tabular}

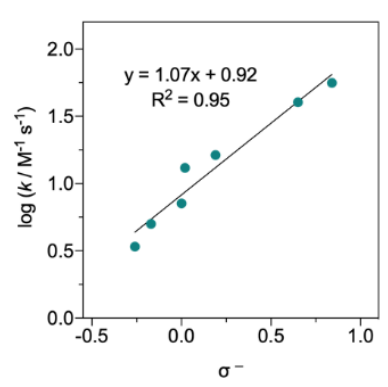

Figure 6. Electronic and steric dependence of oxidative addition. $\mathrm{X}=\mathrm{Cl}$ or $\mathrm{Br}$.

The steric dependence of the oxidative addition was next examined. Relative to $\mathrm{PhBr}$, the addition of one or two ortho-methyl groups reduces the rate of oxidative addition by a factor of 5 or 100 , respectively, with no change in the rate law (Figure $6)$. The sensitivity to steric hindrance is consistent with an inner-sphere process, which may be expected to have a greater steric dependence compared to an outer-sphere electron transfer. ${ }^{47}$

Evaluation of radical intermediates. The above Hammett analysis does not clearly distinguish between concerted (C1) and halogen abstraction (C3) pathways. Therefore, additional experiments were conducted to evaluate the intermediacy of aryl radicals. Standard radical trapping experiments were occluded by decomposition of $\mathbf{1}$ in the presence of TEMPO. Thus, a radical clock experiment was devised in which 1 was reacted with 1-bromo-2-isopentylbenzene. In the event of aryl radical generation, a weak tertiary $\mathrm{C}-\mathrm{H}$ bond is aptly positioned for 1,5-hydrogen atom transfer (HAT), which we have independently measured to occur with a rate of $k_{1,5-\mathrm{HAT}} \sim 2.3 \times 10^{7}$ $\mathrm{s}^{-1}$ (see SI). Upon treating 1 with 1-bromo-2-isopentylbenzene, oxidative addition occurred analogously to reactions with all other aryl bromides; no other species derived from the aryl bromide were detected by ${ }^{1} \mathrm{H}$ NMR (Figure 7A, S19, S20). The lack of products formed by 1,5-HAT rules out a mechanism in which a freely diffusing aryl radical is generated by one $\mathrm{Ni}$ center and trapped at another (A3). Specifically, the rapid rate of 1,5-HAT would enable it to compete with even a diffusion-limited radical capture under the experimental conditions $([\mathrm{Ni}]<1 \mathrm{mM})$.

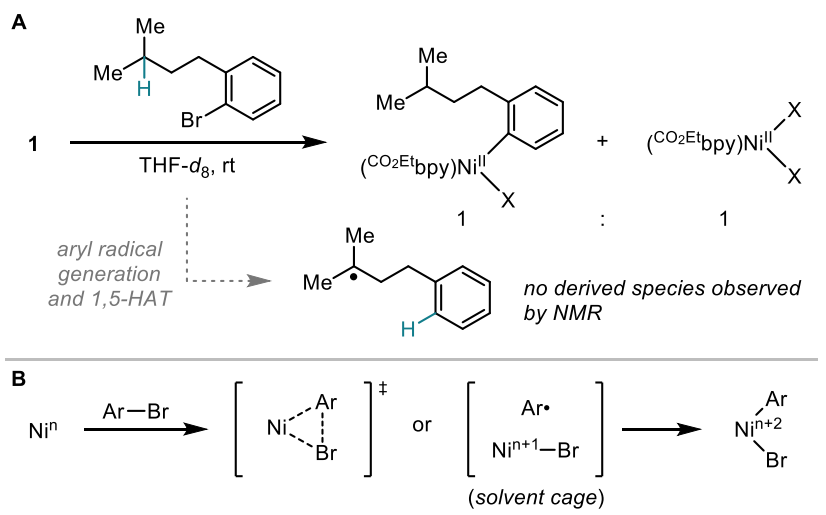

Figure 7. (A) Radical clock experiment. $\mathrm{X}=\mathrm{Cl}$ or $\mathrm{Br}$. (B) Possible mechanisms for $\mathrm{C}-\mathrm{Br}$ bond activation.

The oxidative addition of aryl bromides to 1 therefore proceeds either through a concerted monometallic mechanism, or through halogen atom abstraction followed by radical rebound at the same Ni center within the solvent cage (Figure 7B). Both possibilities result in a two-electron oxidative addition at a single Ni center.

Evaluation of $\mathrm{Ni}(\mathrm{III})$ intermediates. At this stage, we returned to the question of whether the reaction of 1 with aryl bromides occurs through a $\mathrm{Ni}(\mathrm{I})$ or $\mathrm{Ni}(0)$ complex (A1 vs. A2). Given our inability to address this based on experiments interrogating $\mathrm{Ni}(0)$ species, we turned our efforts to observing $\mathrm{Ni}$ (III) species that might result from oxidative addition to $\mathrm{Ni}(\mathrm{I})$.

Since any formed Ni(III) species is likely prone to comproportionation with remaining $\mathrm{Ni}(\mathrm{I})$, adequate stabilization of $\mathrm{Ni}$ (III) against this pathway would be important for success. We drew inspiration from the Mirica group, which demonstrated that pyridinophane-type ligands can provide stable Ni(III) aryl complexes upon 1-electron oxidation of a Ni(II) precursor. ${ }^{48-52}$ Based on the stability conferred by this ligand scaffold, we reasoned that a pyridinophane-type aryl bromide may allow observation of a $\mathrm{Ni}$ (III) complex following oxidative addition to $\mathbf{1}$. Indeed, while our studies were underway, the Mirica group reported that a tridentate pyridinophane ligand enabled direct observation of a $\mathrm{Ni}(\mathrm{I}) \rightarrow \mathrm{Ni}(\mathrm{III})$ oxidative addition by EPR spectroscopy. ${ }^{25}$

Treating 1 with pyridinophane-type aryl bromide 3 resulted in the Ni(III) complex 4, which was characterized by HRMS, EPR, and a low-resolution X-ray crystal structure that confirmed the atom connectivity (Figure 8A, S1, S2). A satisfactory, higher-quality crystal structure was obtained following exchange of the mixed halides with excess $\mathrm{LiCl}$ to afford $\mathbf{5}$. The obtained solid-state structure unambiguously established the formation of a $\mathrm{Ni}(\mathrm{III})$ complex, occurring with loss of the $\mathrm{CO}_{2} \mathrm{Et}$ bpy ligand (Figure 8B). ${ }^{53}$ The EPR spectrum of $5(1: 1$ $\mathrm{PhMe} / \mathrm{MeOH}, 77 \mathrm{~K}$ ) exhibits a rhombic signal consistent with previously characterized $\mathrm{Ni}$ (III) complexes bearing the same ligand scaffold (Figure 8C). ${ }^{48,50,54}$ 
A.

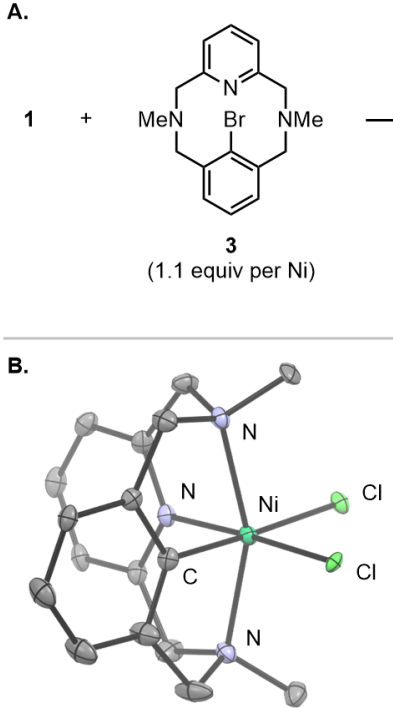

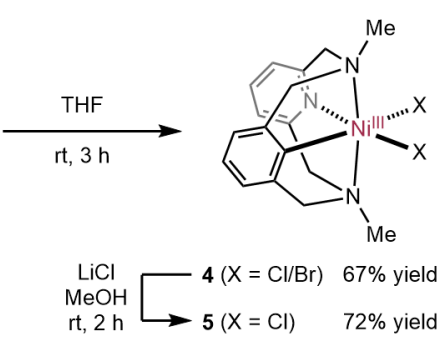

C.

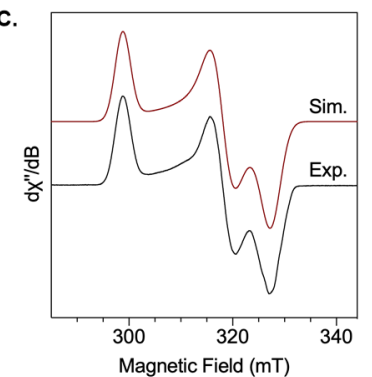

Figure 8. (A) Stoichiometric formation of a Ni(III) aryl complex by oxidative addition to 1. (B) Solid-state molecular structure of 5 at $30 \%$ probability ellipsoids. Hydrogen atoms omitted for clarity. (C) X-band EPR spectrum of 5 (1:1 PhMe/MeOH, $77 \mathrm{~K})$. Simulation parameters: $g_{1}=2.245, g_{2}=2.109, g_{3}=2.049$.

To the best of our knowledge, this is the first stoichiometric generation of a Ni(III) complex by oxidative addition of an aryl halide to any $\mathrm{Ni}(\mathrm{I})$ system. ${ }^{55}$ Our earlier experiments showed that oxidative addition has a first-order dependence on 1, which exists to a significant degree as a Ni(I) monomer. Taken together, these findings are most readily explained by oxidative addition of aryl bromides to $\mathbf{1}$ occurring from the Ni(I) oxidation state (A1). In the particular case of $\mathbf{3}$, however, we cannot rule out a mechanism involving two disproportionations (see SI section 7).

Altogether, our combined results are consistent with an oxidative addition that occurs to form a $\mathrm{Ni}(\mathrm{III})$ complex prior to comproportionation with the $\mathrm{Ni}(\mathrm{I})$ starting material (A1). This process occurs from a monomeric Ni(I) complex (B1) through either a concerted mechanism $(\mathrm{C} 1)$ or halogen abstraction followed by rapid rebound within the solvent cage (C3). Overall, our findings lend credence to the commonly proposed generation $\mathrm{Ni}(\mathrm{III})$ aryl species by oxidative addition of an aryl halide to a monomeric $\mathrm{Ni}(\mathrm{I})$-bpy complex.

\section{CONCLUSION}

In summary, we have synthesized the well-defined $\mathrm{Ni}(\mathrm{I})$ complex 1 and studied its speciation and oxidative addition reactivity. Its solution-phase speciation is characterized by a redox equilibrium with $\mathrm{Ni}(0)$ and $\mathrm{Ni}(\mathrm{II})$ species that can be perturbed by $\pi$-acceptors or $\sigma$-donors. 1 readily undergoes a formal bimetallic oxidative addition with aryl bromides. Mechanistic experiments are consistent with this process occurring through an initial $\mathrm{Ni}(\mathrm{I}) \rightarrow \mathrm{Ni}$ (III) oxidative addition, which was demonstrated stoichiometrically with a pyridinophane-type aryl halide. Our study also highlighted that the supporting ligand can dramatically affect speciation and reactivity, providing 1 with far greater oxidative addition reactivity than its dtbbpy counterpart. While much remains to be learned about Ni(I)-bpy/phen complexes, this work represents a significant step towards

understanding the properties and reactivity of these important species.

\section{ASSOCIATED CONTENT}

Supporting Information

The Supporting Information is available free of charge at http://pubs.acs.org/

Experimental procedures, experimental data, and characterization and spectral data for new compounds (PDF)

\section{Accession Codes}

CCDC 2141424-2141425 contain the supplementary crystallographic data for this paper. These data can be obtained free of charge via www.ccdc.cam.ac.uk/data_request/cif, or by emailing data request@ccdc.cam.ac.uk, or by contacting The Cambridge Crystallographic Data Centre, 12 Union Road, Cambridge CB2 1EZ, UK; fax: +44 1223336033 .

\section{AUTHOR INFORMATION}

\section{Corresponding Author}

*agdoyle@chem.ucla.edu

\section{ORCID}

Stephen I. Ting: 0000-0002-6146-8112

Wendy L. Williams: 0000-0003-2227-0856

Abigail G. Doyle: 0000-0002-6641-0833

\section{Notes}

The authors declare no competing financial interest.

\section{ACKNOWLEDGMENT}

We thank Dr. Phil Jeffrey and Dr. Saeed Khan for assistance with X-ray crystal structure determinations, Dr. John Eng and Dr. Paul Oyala for assistance with EPR measurements, Boran Lee for assistance with solid-state magnetic moment measurements, Alana Rose Meyer and Roberto Chavez for assistance with photolysis experiments, and Dr. Megan Mohadjer Beromi and Prof. Liviu Mirica for helpful discussions. Financial support for this project was provided by BioLEC (an Energy Frontier Research Center funded by the U.S. Department of Energy, Office of Science, Office of Basic Energy Sciences under Award no. DE-SC0019370) and NIGMS (R35 GM126986).

\section{REFERENCES}

(1) Tasker, S. Z.; Standley, E. A.; Jamison, T. F. Recent Advances in Homogeneous Nickel Catalysis. Nature 2014, 509, 299-309.

(2) Ananikov, V. P. Nickel: The "Spirited Horse" of Transition Metal Catalysis. ACS Catal. 2015, 5, 1964-1971.

(3) Twilton, J.; Le, C.; Zhang, P.; Shaw, M. H.; Evans, R. W.; MacMillan, D. W. C. The Merger of Transition Metal and Photocatalysis. Nat. Rev. Chem. 2017, 1, 0052.

(4) Richmond, E.; Moran, J. Recent Advances in Nickel Catalysis Enabled by Stoichiometric Metallic Reducing Agents. Synthesis 2017, 50, 499-513.

(5) Milligan, J. A.; Phelan, J. P.; Badir, S. O.; Molander, G. A. Alkyl Carbon-Carbon Bond Formation by Nickel/Photoredox Cross-Coupling. Angew. Chem. Int. Ed. 2019, 58, 6152-6163.

(6) Chan, A. Y.; Perry, I. B.; Bissonnette, N. B.; Buksh, B. F.; Edwards, G. A.; Frye, L. I.; Garry, O. L.; Lavagnino, M. N.; Li, B. X.; Liang, Y.; Mao, E.; Millet, A.; Oakley, J. V.; Reed, N. L.; Sakai, H. A.; Seath, C. P.; MacMillan, D. W. C. Metallaphotoredox: The Merger of Photoredox and Transition Metal Catalysis. Chem. Rev. 2021, DOI: 10.1021/acs.chemrev.1c00383.

(7) Malapit, C. A.; Prater, M. B.; Cabrera-Pardo, J. R.; Li, M.; Pham, T. D.; McFadden, T. P.; Blank, S.; Minteer, S. D. Advances on the 
Merger of Electrochemistry and Transition Metal Catalysis for Organic Synthesis. Chem. Rev. 2021, DOI: 10.1021/acs.chemrev.1c00614.

(8) Diccianni, J. B.; Diao, T. Mechanisms of Nickel-Catalyzed Cross-Coupling Reactions. Trends Chem. 2019, 1, 830-844.

(9) Budnikova, Y.; Vicic, D.; Klein, A.; Budnikova, Y. H.; Vicic, D. A.; Klein, A. Exploring Mechanisms in Ni Terpyridine Catalyzed C-C Cross-Coupling Reactions-A Review. Inorganics 2018, 6, 18.

(10) Sun, R.; Qin, Y.; Ruccolo, S.; Schnedermann, C.; Costentin, C.; Nocera, D. G. Elucidation of a Redox-Mediated Reaction Cycle for Nickel-Catalyzed Cross Coupling. J. Am. Chem. Soc. 2019, 141, 8993.

(11) Yang, L.; Lu, H.; Lai, C.; Li, G.; Zhang, W.; Cao, R.; Liu, F.; Wang, C.; Xiao, J.; Xue, D. Light-Promoted Nickel Catalysis: Etherification of Aryl Electrophiles with Alcohols Catalyzed by a Ni ${ }^{\mathrm{II}}$-Aryl Complex. Angew. Chem. Int. Ed. 2020, 59, 12714-12719.

(12) Till, N. A.; Tian, L.; Dong, Z.; Scholes, G. D.; MacMillan, D W. C. Mechanistic Analysis of Metallaphotoredox C-N Coupling: Photocatalysis Initiates and Perpetuates Ni(I)/Ni(III) Coupling Activity. J. Am. Chem. Soc. 2020, 142, 15830-15841.

(13) Qin, Y.; Sun, R.; Gianoulis, N. P.; Nocera, D. G. Photoredox Nickel-Catalyzed C-S Cross-Coupling: Mechanism, Kinetics, and Generalization. J. Am. Chem. Soc. 2021, 143, 2005-2015.

(14) Bernhard, S. S. R.; Locke, G. M.; Plunkett, S.; Meindl, A.; Flanagan, K. J.; Senge, M. O. Cubane Cross-Coupling and CubanePorphyrin Arrays. Chem. Eur. J. 2018, 24, 1026-1030.

(15) Ping, Y.; Wang, K.; Pan, Q.; Ding, Z.; Zhou, Z.; Guo, Y.; Kong, W. Ni-Catalyzed Regio- and Enantioselective Domino Reductive Cyclization: One-Pot Synthesis of 2,3-Fused Cyclopentannulated Indolines. ACS Catal. 2019, 9, 7335-7342.

(16) Wang, J.; Cary, B. P.; Beyer, P. D.; Gellman, S. H.; Weix, D. J. Ketones from Nickel-Catalyzed Decarboxylative, Non-Symmetric Cross-Electrophile Coupling of Carboxylic Acid Esters. Angew. Chem. Int. Ed. 2019, 58, 12081-12085.

(17) Xi, X.; Luo, Y.; Li, W.; Xu, M.; Zhao, H.; Chen, Y.; Zheng, S.; Qi, X.; Yuan, W. From Esters to Ketones via a Photoredox-Assisted Reductive Acyl Cross-Coupling Strategy. Angew. Chem. Int. Ed. 2021.

(18) Powers, D. C.; Anderson, B. L.; Nocera, D. G. Two-Electron $\mathrm{HCl}$ to $\mathrm{H}_{2}$ Photocycle Promoted by Ni(II) Polypyridyl Halide Complexes. J. Am. Chem. Soc. 2013, 135, 18876-18883.

(19) $[(\mathrm{dtbbpy}) \mathrm{NiCl}]_{2}$ has an electronic structure described as $\left[\left(\text { dtbbpy }^{-}\right) \mathrm{Ni}^{\mathrm{II}} \mathrm{Cl}\right]_{2}$, but is referred to as a $\mathrm{Ni}(\mathrm{I})$ complex for simplicity. Mohadjer Beromi, M.; Brudvig, G. W.; Hazari, N.; Lant, H. M. C.; Mercado, B. Q. Synthesis and Reactivity of Paramagnetic Nickel Polypyridyl Complexes Relevant to $\mathrm{C}\left(\mathrm{sp}^{2}\right)-\mathrm{C}\left(\mathrm{sp}^{3}\right)$ Coupling Reactions. Angew. Chem. Int. Ed. 2019, 58, 6094-6098.

(20) Lin, Q.; Diao, T. Mechanism of Ni-Catalyzed Reductive 1,2Dicarbofunctionalization of Alkenes. J. Am. Chem. Soc. 2019, 141, 17937-17948.

(21) Somerville, R. J.; Odena, C.; Obst, M. F.; Hazari, N.; Hopmann, K. H.; Martin, R. Ni(I)-Alkyl Complexes Bearing Phenanthroline Ligands: Experimental Evidence for $\mathrm{CO}_{2}$ Insertion at $\mathrm{Ni}$ (I) Centers. J. Am. Chem. Soc. 2020, 142, 10936-10941.

(22) Humphrey, E. J.; Kennedy, A.; Sproules, S.; Nelson, D. Evaluating a Dispersion of Sodium in Sodium Chloride for the Synthesis of Low-Valent Nickel Complexes. ChemRxiv 2021, DOI: 10.26434/chemrxiv-2021-mgmw0.

(23) Kawamata, Y.; Vantourout, J. C.; Hickey, D. P.; Bai, P.; Chen, L.; Hou, Q.; Qiao, W.; Barman, K.; Edwards, M. A.; Garrido-Castro, A. F.; deGruyter, J. N.; Nakamura, H.; Knouse, K.; Qin, C.; Clay, K. J.; Bao, D.; Li, C.; Starr, J. T.; Garcia-Irizarry, C.; Sach, N.; White, H. S.; Neurock, M.; Minteer, S. D.; Baran, P. S. Electrochemically Driven, Ni-Catalyzed Aryl Amination: Scope, Mechanism, and Applications. J. Am. Chem. Soc. 2019, 141, 6392-6402.

(24) Till, N. A.; Oh, S.; MacMillan, D. W. C.; Bird, M. J. The Application of Pulse Radiolysis to the Study of Ni(I) Intermediates in NiCatalyzed Cross-Coupling Reactions. J. Am. Chem. Soc. 2021, 143, 9332-9337.

(25) Mirica, L.; Na, H. Deciphering the Mechanism of the Ni-Photocatalyzed $\mathrm{C}-\mathrm{O}$ Cross-Coupling Reaction Using a Tridentate Pyridinophane Ligand. ChemRxiv 2021, DOI: 10.33774/chemrxiv-2021cwk2r.
(26) Inatomi, T.; Fukahori, Y.; Yamada, Y.; Ishikawa, R.; Kanegawa, S.; Koga, Y.; Matsubara, K. Ni(I)-Ni(III) Cycle in BuchwaldHartwig Amination of Aryl Bromide Mediated by NHC-Ligated Ni(I) Complexes. Catal. Sci. Technol. 2019, 9, 1784-1793.

(27) King, A. E.; Stieber, S. C. E.; Henson, N. J.; Kozimor, S. A.; Scott, B. L.; Smythe, N. C.; Sutton, A. D.; Gordon, J. C. Ni(bpy)(cod): A Convenient Entryway into the Efficient Hydroboration of Ketones, Aldehydes, and Imines. Eur. J. Inorg. Chem. 2016, 2016, 1635-1640.

(28) Cagan, D. A.; Stroscio, G. D.; Cusumano, A. Q.; Hadt, R. G. Multireference Description of Nickel-Aryl Homolytic Bond Dissociation Processes in Photoredox Catalysis. J. Phys. Chem. A 2020, 124, 9915-9922.

(29) Ting, S. I.; Garakyaraghi, S.; Taliaferro, C. M.; Shields, B. J.; Scholes, G. D.; Castellano, F. N.; Doyle, A. G. ${ }^{3}$ d-d Excited States of $\mathrm{Ni}(\mathrm{II})$ Complexes Relevant to Photoredox Catalysis: Spectroscopic Identification and Mechanistic Implications. J. Am. Chem. Soc. 2020, $142,5800-5810$.

(30) Yamamoto, T.; Wakabayashi, S.; Osakada, K. Mechanism of $\mathrm{C}-\mathrm{C}$ Coupling Reactions of Aromatic Halides, Promoted by Ni(COD) 2 in the Presence of 2,2'-Bipyridine and $\mathrm{PPh}_{3}$, to Give Biaryls. J. Organomet. Chem. 1992, 428, 223-237.

(31) Beattie, D. D.; Lascoumettes, G.; Kennepohl, P.; Love, J. A.; Schafer, L. L. Disproportionation Reactions of an Organometallic Ni(I) Amidate Complex: Scope and Mechanistic Investigations. Organometallics 2018, 37, 1392-1399.

(32) Matsubara, K.; Fukahori, Y.; Inatomi, T.; Tazaki, S.; Yamada, Y.; Koga, Y.; Kanegawa, S.; Nakamura, T. Monomeric Three-Coordinate $\mathrm{N}$-Heterocyclic Carbene Nickel(I) Complexes: Synthesis, Structures, and Catalytic Applications in Cross-Coupling Reactions. Organometallics 2016, 35, 3281-3287.

(33) We draw ( ${ }^{C O 2 E t}$ bpy) $\mathrm{NiX}_{2}$ as a four-coordinate complex for simplicity. More precisely, however, this should be taken to reflect composition rather than structure, which is likely complicated by the formation of dimers, oligomers, and nickelate salts. For selected references, see SI.

(34) Diccianni, J. B.; Katigbak, J.; Hu, C.; Diao, T. Mechanistic Characterization of (Xantphos)Ni(I)-Mediated Alkyl Bromide Activation: Oxidative Addition, Electron Transfer, or Halogen-Atom Abstraction. J. Am. Chem. Soc. 2019, 141, 1788-1796.

(35) Schley, N. D.; Fu, G. C. Nickel-Catalyzed Negishi Arylations of Propargylic Bromides: A Mechanistic Investigation. J. Am. Chem. Soc. 2014, 136, 16588-16593.

(36) Matsubara, K.; Yamamoto, H.; Miyazaki, S.; Inatomi, T.; Nonaka, K.; Koga, Y.; Yamada, Y.; Veiros, L. F.; Kirchner, K. Dinuclear Systems in the Efficient Nickel-Catalyzed Kumada-Tamao-Corriu Cross-Coupling of Aryl Halides. Organometallics 2016, 36, 255-265.

(37) Dürr, A. B.; Fisher, H. C.; Kalvet, I.; Truong, K.-N.; Schoenebeck, F. Divergent Reactivity of a Dinuclear (NHC)Nickel(I) Catalyst versus Nickel(0) Enables Chemoselective Trifluoromethylselenolation. Angew. Chem. Int. Ed. 2017, 56, 13431-13435.

(38) Gutierrez, O.; Tellis, J. C.; Primer, D. N.; Molander, G. A.; Kozlowski, M. C. Nickel-Catalyzed Cross-Coupling of Photoredox-Generated Radicals: Uncovering a General Manifold for Stereoconvergence in Nickel-Catalyzed Cross-Couplings. J. Am. Chem. Soc. 2015, $137,4896-4899$.

(39) Yuan, M.; Song, Z.; Badir, S. O.; Molander, G. A.; Gutierrez, O. On the Nature of $\mathrm{C}\left(\mathrm{sp}^{3}\right)-\mathrm{C}\left(\mathrm{sp}^{2}\right)$ Bond Formation in Nickel-Catalyzed Tertiary Radical Cross-Couplings: A Case Study of Ni/Photoredox Catalytic Cross-Coupling of Alkyl Radicals and Aryl Halides. J. Am. Chem. Soc. 2020.

(40) Maity, B.; Zhu, C.; Yue, H.; Huang, L.; Harb, M.; Minenkov, Y.; Rueping, M.; Cavallo, L. Mechanistic Insight into the PhotoredoxNickel-HAT Triple Catalyzed Arylation and Alkylation of $\alpha$-Amino $\mathrm{C}_{\mathrm{sp} 3}-\mathrm{H}$ Bonds. J. Am. Chem. Soc. 2020, 142, 16942-16952.

(41) Ligand dissociation from $\mathrm{Ni}\left(\mathrm{PEt}_{3}\right)_{4}$ is required prior to oxidative addition, and this equilibrium contributes to the measured rate constant. Based on the measured $K_{\mathrm{D}}$ in this reference, $\sim 95 \%$ of the $\mathrm{Ni}\left(\mathrm{PEt}_{3}\right)_{4}$ exists as the kinetically relevant $\mathrm{Ni}\left(\mathrm{PEt}_{3}\right)_{3}$ under the conditions for kinetic measurements. Our measured rate constant with 1 similarly includes contributions from speciation equilibria. Tsou, T. T.; Kochi, J. K. Mechanism of Oxidative Addition. Reaction of Nickel(0) 
Complexes with Aromatic Halides. J. Am. Chem. Soc. 1979, 101, 6319-6332.

(42) Portnoy, M.; Milstein, D. Mechanism of Aryl Chloride Oxidative Addition to Chelated Palladium(0) Complexes. Organometallics 1993, 12, 1665-1673.

(43) The authors of ref. 24 report $\rho=+3.1$ for a Hammett plot constructed using $\ln \left(k_{\mathrm{R}} / k_{\mathrm{H}}\right)$ instead of $\log \left(k_{\mathrm{R}} / k_{\mathrm{H}}\right)$.

(44) Goossen, L. J.; Koley, D.; Hermann, H. L.; Thiel, W. Mechanistic Pathways for Oxidative Addition of Aryl Halides to Palladium(0) Complexes: A DFT Study. Organometallics 2005, 24, 2398-2410.

(45) Biscoe, M. R.; Fors, B. P.; Buchwald, S. L. A New Class of Easily Activated Palladium Precatalysts for Facile C-N Cross-Coupling Reactions and the Low Temperature Oxidative Addition of Aryl Chlorides. J. Am. Chem. Soc. 2008, 130, 6686-6687.

(46) This $\rho$ value was computed by DFT. Pérez-García, P. M.; Darù, A.; Scheerder, A. R.; Lutz, M.; Harvey, J. N.; Moret, M.-E. Oxidative Addition of Aryl Halides to a Triphosphine Ni(0) Center to Form Pentacoordinate Ni(II) Aryl Species. Organometallics 2020, 39, 1139 1144.

(47) Wong, C. L.; Kochi, J. K. Electron Transfer with Organometals. Steric Effects as Probes for Outer-Sphere and Inner-Sphere Oxidations of Homoleptic Alkylmetals with Iron(III) and Iridate(IV) Complexes. J. Am. Chem. Soc. 1979, 101, 5593-5603.

(48) Zhou, W.; Schultz, J. W.; Rath, N. P.; Mirica, L. M. Aromatic Methoxylation and Hydroxylation by Organometallic High-Valent Nickel Complexes. J. Am. Chem. Soc. 2015, 137, 7604-7607.

(49) Zheng, B.; Tang, F.; Luo, J.; Schultz, J. W.; Rath, N. P.; Mirica, L. M. Organometallic Nickel(III) Complexes Relevant to Cross-
Coupling and Carbon-Heteroatom Bond Formation Reactions. J. Am. Chem. Soc. 2014, 136, 6499-6504.

(50) Zhou, W.; Watson, M. B.; Zheng, S.; Rath, N. P.; Mirica, L. M. Ligand Effects on the Properties of Ni(III) Complexes: AerobicallyInduced Aromatic Cyanation at Room Temperature. Dalton Trans. 2016, 45, 15886-15893.

(51) Schultz, J. W.; Fuchigami, K.; Zheng, B.; Rath, N. P.; Mirica, L. M. Isolated Organometallic Nickel(III) and Nickel(IV) Complexes Relevant to Carbon-Carbon Bond Formation Reactions. J. Am. Chem. Soc. 2016, 138, 12928-12934.

(52) Smith, S. M.; Planas, O.; Gómez, L.; Rath, N. P.; Ribas, X.; Mirica, L. M. Aerobic C-C and C-O Bond Formation Reactions Mediated by High-Valent Nickel Species. Chem. Sci. 2019, 10, 1036610372.

(53) 3 reacts with 1 more quickly than $2,6-\mathrm{Me}_{2}-\mathrm{C}_{6} \mathrm{H}_{3} \mathrm{Br}$ does, indicating coordination through the pendant nitrogens. However, it is unknown whether loss of the CO2Etbpy ligand occurs before or after oxidative addition to the aryl bromide moiety of $\mathbf{3}$.

(54) Zhou, W.; Zheng, S.; Schultz, J. W.; Rath, N. P.; Mirica, L. M. Aromatic Cyanoalkylation through Double C-H Activation Mediated by Ni(III). J. Am. Chem. Soc. 2016, 138, 5777-5780.

(55) A stoichiometric $\mathrm{Ni}(\mathrm{I}) \rightarrow \mathrm{Ni}(\mathrm{III})$ oxidative addition of $\mathrm{MeI}$ has been reported. Lipschutz, M. I.; Tilley, T. D. Carbon-Carbon CrossCoupling Reactions Catalyzed by a Two-Coordinate Nickel(II)Bis(Amido) Complex via Observable $\mathrm{Ni}^{\mathrm{I}}, \mathrm{Ni}^{\mathrm{II}}$, and $\mathrm{Ni}^{\mathrm{II}}$ Intermediates. Angew. Chem. Int. Ed. 2014, 53, 7290-7294.

Authors are required to submit a graphic entry for the Table of Contents (TOC) that, in conjunction with the manuscript title, should give the reader a representative idea of one of the following: A key structure, reaction, equation, concept, or theorem, etc., that is discussed in the manuscript. Consult the journal's Instructions for Authors for TOC graphic specifications.

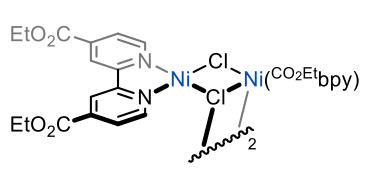

Nickel(I) (X-ray)

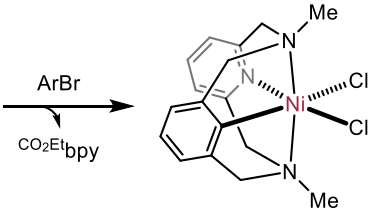

Nickel(III) (X-ray)

- stoichiometric formation using pyridinophane $\mathrm{ArBr}$
- redox equilibrium - oxidative addition reactivity

- mechanistic studies 